\title{
GENETIC DIMORPHISM IN FRUIT TYPES IN AEGILOPS SPELTOIDES
}

\author{
D. ZOHARY and D. IMBER \\ Department of Botany, The Hebrew University, Jerusalem, Israel
}

\section{INTRODUCTION}

Received 22.xi.62

THERE are two main morphological types in the diploid group of Agilops speltoides Tausch. These types differ markedly in the structure of their fruiting spike and consequently in their mode of seed dispersal (see fig. I).

(a) Speltoides plants (AE. speltoides Tausch, according to Eig's classification, 1929 or $\mathscr{E}$. aucheri Boiss. according to Zhukovsky, 1928) have a long cylindrical spike with relatively widely interspersed spikelets. Only the apical spikelet is awned. The rachis of the spike is tough except for a brittle node at its base. Upon maturity the entire spike is detached as a long, cylindrial, many-seeded dispersal unit and remains as such on the soil surface throughout the summer.

(b) Ligustica plants (E. ligustica Coss., sensu Eig, 1929) have denser, two-rowed ears, in which the lateral spikelets are also awned. The rachis is brittle at every joint, so that the mature spike disarticulates into wedge-shaped, 2-3 seeded spikelets. Each individual spikelet thus serves as an independent dissemination unit; it is mechanically adapted to insert itself into the ground and usually buries itself soon after detachment.

The speltoides-ligustica types have puzzled wheat students as to the nature of their mutual relationships. On the one hand one is confronted here with remarkable morphological differences and rarity of intermediate types. This led the two main monographers of the genus Egilops (Zhukovsky, I928; Eig, 1929) to look upon these two types as distinct species. On the other hand, in several respects the pair does not fit into ordinary models of speciation. The morphological differences between speltoides and ligustica plants are restricted to the fruiting spike alone. In all other traits, such as vegetative characters and phenological behaviour, the types are strikingly similar to each other (Miczynski, 1926; Schiemann, 1928). In addition, hybrids between the two types are fully fertile and show complete pairing of chromosomes in meiosis. Furthermore, breeding experiments by various workers (Miczynsky, I926 ; Schiemann, I928 ; Eig, 1929; Kihara and Lilienfeld, 1932) revealed that the manifold differences in spike morphology are inherited in a more or less monohybrid mendelian fashion (dominance of ligustica over speltoides in $\mathrm{F}_{1}$, and $3:$ I segregation in $\mathrm{F}_{2}$ ). These data were first interpreted as indicating the presence of only a single pleiotropic gene. But Sears 
(1941) on a basis of occasional occurrence of recombinants or intermediate plants, proposed the operation of a block of closely linked genes.

Further indications of the close relationships between speltoides and ligustica plants were provided by data on their sympatric distribution, and the occurrence of mixed stands of the two types (Eig, 1929). Close genetic connections were revealed also by data on occasional segregation, found in plants grown from seed of original collections (Schiemann, 1928 ; Eig, 1929), as well as in the progeny of parents propagated in experimental plots by several workers.

On a basis of this information-and apparently also on the assumption that these plants were predominately self-pollinated-most students (i.e. Kihara and Lilienfeld, 1932; Sears, 1941 ; Bowden, 1960) have tended to regard speltoides and ligustica plants as two distinct forms or subspecies of the single species $E$. speltoides.

We have attempted to gain a better understanding of the relationships between speltoides and ligustica types through examination of natural populations, their distribution and composition, as well as their genotypic structure and pollination behaviour. The purpose of this paper is to question the validity of the concept that speltoides and ligustica types are independent units. Evidence is brought to indicate that these two types are spatially and genetically interconnected and form common, largely panmictic populations. The two types are presented as constituting a case of population dimorphism in fruit structure.

\section{DISTRIBUTION AND COMPOSITION OF POPULATIONS}

Already Eig (1929) noted the peculiar pattern of distribution of speltoides and ligustica plants: the two types have more or less overlapping distribution areas, moreover, they occur side-by-side in mixed populations. Eig himself found mixed stands to be the rule in Israel -i.e. in the southernmost outpost of the range of the two types. But he also strongly suspected such mixed stands to be rather universal and to occur in the other parts of these types' distribution area, namely in Turkey, Syria and Iraq. Eig arrived at this conclusion through his findings in herbarium material : in many instances both speltoides and ligustica plants had been collected in the same locality.

We re-examined the distribution patterns of ligustica and speltoides plants in Israel and in Turkey. In Israel a survey was made of most of the known stands, both the in the Coastal Plain and on Mt. Carmel. Visits to Turkey were made by the senior author in 1959 and 1962. Special attention was paid to southern Turkey (districts of Adana, Marash, Gaziantep and Malatya), the known centre of this group (Eig, 1929). In this area speltoides and ligustica plants reach their highest abundance and their widest ecological amplitude. Over 60 localities were examined in Turkey. These included a variety of habitats from Mediterranean dwarf-shrub formations, degraded park 
forests of oak and steppe-like herbaceous formations to alluvial plains and field borders.

All over Israel and Turkey speltoides and ligustica plants were found to grow in mixed populations. There were wide fluctuations in the proportions between ligustica and speltoides in different sites and in different plant formations. But both types were almost universally present in the stations examined. In many stands ligustica and speltoides plants were more or less evenly mixed; in others, ligustica plants predominated and reached frequencies of $9^{\circ}$ per cent. or more. Still in other stations the situation was reversed, and speltoides plants occurred in an overwhelming majority. Occasionally we met with almost pure speltoides or ligustica stands, in which the rare type could only be detected upon careful field examination. But throughout Israel and Turkey we only came across very few instances of genuinely pure populations of either type. Conspicuous among these were some extensive ligustica stands encountered in the high and cold continental plateau (altitude I000-I $400 \mathrm{~m}$.) of the Elazig-Tunceli area in central Turkey. Similar large ligustica stands were found in Turkish Thrace along the Istanbul-Alexandropolis road. Both locations are in the northern (or colder) fringe of the distribution of this group. Several pure but relatively small stands of speltoides plants were found in the area of Mt. Carmel, Israel, and in the hills of Gaziantep, Turkey.

There are good indications that mixed populations similar to those of southern Turkey occur also further east-in Iraqui Kurdistan (i.e. in the foothills bordering the Euphrates-Tigris basin). This is indicated by numerous and recent collections, particularly the ones of $\mathrm{J}$. B. Gillett located in Kew Herbarium. In his collections Gillett was careful to note that these two types are found growing together in the Erbil, Amadiya and Mosul districts of northern Iraq.

These data, which can be further supplemented by scattered remarks of several botanists and collectors warrant the conclusion that mixed populations are the rule, not only in Israel but also elsewhere: speltoides and ligustica plants are apparently spatially interconnected almost throughout their distribution area.

Attention should also be drawn to the occurrence of intermediate or recombination types in mixed speltoides-ligustica populations, e.g. plants with laterally awned but tough spikes (var. polyathera according to Eig, I929) or also very occasionally plants with brittle but laterally awnless spikes. Such intermediates are rare; they usually occur in frequencies of less than $0 \cdot 1-0 \cdot 2$ per cent., yet they were detected in most populations where a careful search for them was made.

\section{PROGENY TESTS}

Progeny tests were performed in individual ligustica and speltoides plants, sampled from a typical natural mixed population which is 
growing $4 \mathrm{~km}$. east of Ashkelon in the southern Coastal Plain of Israel. These tests were made with the purpose of obtaining information: (a) on the genotypic constitution of a natural mixed population; $(b)$ on the nature of the mating system operating in such a population. The results of these tests are summarised in tables I and 2.

The mixed population at Ashkelon was examined in the summers of 1961 and 1962 . In both years it was found to contain 80 per cent.

TABLE $\mathbf{r}$

Progeny tests of the mixed population at Ashkelon (2o per cent. speltoides80 per cent. ligustica): segregating vs. non-segregating parents

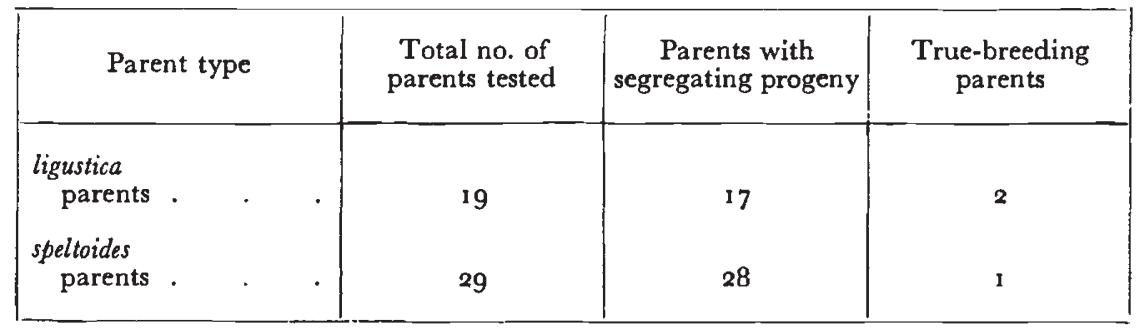

TABLE 2

Progeny tests of the mixed population at Ashkelon (20 per cent. speltoides80 per cent. ligustica): types and proportions of progeny obtained

\begin{tabular}{|c|c|c|c|c|c|}
\hline Parent type & $\begin{array}{l}\text { Total no. } \\
\text { of parents } \\
\text { tested }\end{array}$ & $\begin{array}{l}\text { Total no. } \\
\text { of progeny } \\
\text { obtained }\end{array}$ & $\begin{array}{l}\text { speltoides } \\
\text { progeny }\end{array}$ & $\begin{array}{l}\text { ligustica } \\
\text { progeny }\end{array}$ & $\begin{array}{l}\text { Intermediate } \\
\text { progeny }\end{array}$ \\
\hline $\begin{array}{l}\text { ligustica } \\
\text { parents }\end{array}$ & 19 & $\begin{array}{c}129 \\
(100 \text { per cent.) }\end{array}$ & $\begin{array}{c}27 \\
(20.95 \text { per cent. })\end{array}$ & $\begin{array}{c}101 \\
(78 \cdot 25 \text { per cent. })\end{array}$ & $\begin{array}{c}\mathrm{I} \\
\text { (0.80 per cent.) }\end{array}$ \\
\hline $\begin{array}{l}\text { speltoides } \\
\text { parents }\end{array}$ & 29 & $\begin{array}{c}189 \\
\text { (1 } 00 \text { per cent.) }\end{array}$ & $\begin{array}{c}1 \text { 1 } 0 \\
(58 \cdot 20 \text { per cent. })\end{array}$ & $\begin{array}{c}67 \\
\text { (35.45 per cent.) }\end{array}$ & $\frac{12}{(6.35 \text { per cent.) }}$ \\
\hline
\end{tabular}

ligustica and 20 per cent. speltoides plants, as well as occasional intermediate forms (less than 0.5 per cent.). The population occurred as a dense and rather uniform stand in depressions in the heavy soil of the alluvial plain, and particularly in the shallow bed of a dry water course (wadi).

Seed from individual ligustica and speltoides plants growing in this habitat was collected in July I961. To avoid mistakes due to density of stands, only a single spike was collected from each parent. Seed from single spikes of 30 speltoides parents and 20 ligustica parents were subsequently planted in Jerusalem in the growing season of $1961-62$. Twenty-nine speltoides and ig ligustica parents produced each 4 progeny or more (average 6.6), and were used in the tests. 


\section{(i) Detection of heterozygous plants}

Since the ligustica condition is dominant over the speltoides condition, ligustica plants should be either homozygous or heterozygous for the ligustica block of genes. Heterozygous ligustica plants should, therefore: segregate to produce both ligustica and speltoides types of progeny. In contrast, homozygous ligustica parents should produce ligustica progeny only. This is true upon self-pollination as well as upon cross-pollination with pollen of the speltoides genotype. The occurrence of one or more speltoides plants among the progeny of an individual ligustica parent was therefore regarded as an indication of its heterozygous constitution. Seventeen of the ig ligustica-type parents produced one or more speltoides progeny, i.e. turned out to be heterozygotes. Considering the small number of progeny raised from each parent (4-IO), the proportion arrived at must be taken as representing a minimum value, and the detection of heterozygotes among the ligustica parents may have been incomplete. The total number of ligustica parents tested (I 9 ) is indeed rather small ; yet the results obtained are rather suggestive : they indicate that a large proportion of the ligustica plants growing in the mixed population at Ashkelon are heterozygotes. Moreover, their frequency exceeds significantly the proportion required under the Hardy-Weinberg equilibrium-for a fully panmictic population of 80 per cent. ligustica and 20 per cent. speltoides plants.

\section{(ii) Estimate of notural cross-pollination}

Since the speltoides plants are homozygous recessive, each speltoides plant growing in a mixed population can serve as a natural tester for cross-pollination by ligustica-type pollen. Obviously such a pollen grain will produce a ligustica progeny. Moreover, from the proportion of the ligustica produced by speltoides testers, the amount of crosspollination in the parent plants can be assessed, provided the gametic proportions of the two pollen genotypes produced in the mixed population are known.

There are two possible estimates for the relative gametic frequencies of speltoides vs. ligustica pollen grains produced by the mixed stands. First, the gametic frequencies can be calculated on a basis of the detected proportions of homozygous to heterozygous ligustica parents. On this assumption the Ashkelon population consisted of 8.5 per cent. homozygous ligustica, 7I.5 per cent. heterozygous ligustica and 20 per cent. speltoides plants. Second, the Ashkelon population can be assumed to fit a Hardy-Weinberg equilibrium and thus to consist of $3 \mathrm{I}^{\circ} \mathrm{O}$ per cent. homozygous ligustica, $49^{\circ} \mathrm{O}$ per cent. heterozygous ligustica and 20.0 per cent. speltoides plants. Speltoides parents tested produced $4_{1} \cdot 8$ per cent. of non-speltoides progeny (ligustica as well as intermediate progeny). This indicates cross-pollination to the extent of 95 per cent. on a basis of the first population model, and one of about 75 per cent. on basis of the second. 


\section{POLLINATION BEHAVIOUR}

The various species of the Egilops-Triticum group are recognised true selfers : in general, members of this group set seed upon selfing ; moreover, their mature anthers open prior to emergence from the floret. Thus part of the pollen is regularly shed inside the floret, and self-pollination is insured.

This pollination behaviour does not occur in ligustica and speltoides plants. Although they set seed upon selfing, they are not cleistogamous. Instead, they possess a floral mechanism which apparently promotes cross-pollination. Anthers emerge from the florets still unsplit. Dehiscence and pollen shedding take place outside the florets after the filaments have elongated. Anthesis is achieved exactly at the same time of day (morning) in both types. Such behaviour was found to be the rule in plants grown from both Israeli and Turkish collections.

This information on floral biology corroborates the estimates on the amount of cross-pollination arrived at on a basis of progeny testing of the speltoides plants. It lends further support to our conclusion that speltoides and ligustica plants are both predominantly cross-pollinated.

\section{DISCUSSION}

The results of progeny tests performed in plants sampled from the Ashkelon population indicate that mixed stands of speltoides and ligustica plants are in fact common populations. In other words, the plants of the two types are genetically interconnected by virtue of a mutual mating system, one of predominantly cross-pollination. This conclusion is also borne out by observation on the pollination behaviour of the two forms. Accordingly, the speltoides and ligustica types should not be regarded as two different species and not even as independent varieties but as two constituents of dimorphic populations of the same species (Ex. speltoides Tausch). Mixed stands of the two types are looked upon as a case of genetically determined fruit dimorphism, where two types of seed dispersal apparatus function in the same population in a complementary way.

Dimorphism in fruit structure, and consequently in seed dispersal mechanisms, is a characteristic feature of a considerable number of plant genera native to the open steppe or steppe-like habitats in the region of Mediterranean agriculture (M. Zohary, 1937). That the formation of two complementary types of diaspores by the same species is apparently a successful trend of adaptive specialisation is also borne out by the fact that fruit dimorphism has developed independently in members of various families such as Composita, Crucifere, Umbellifera and Graminea. But all cases of fruit dimorphism so far known involve plants in which two (or more) types of fruit are produced by the same individual. They are, therefore, cases of 
phenotypically determined fruit dimorphism where the development of the two kinds of fruit is controlled by differentiation processes only. In the speltoides-ligustica pair, however, two kinds of dispersal units are borne on different individuals: two types of plants which differ with regard to their fruit structure form a common population. This is an instance of genetically determined fruit dimorphism, with a population as its unit of operation.

A model of population dimorphism in seed dispersal apparatus provides a simple explanation to several, previously puzzling, features of the speltoides-ligustica pair. The almost universal occurrence of mixed stands throughout the larger part of the distribution area of these two types makes sense. Such a model can also explain why early workers such as Schiemann (1928) and Eig (1929) found frequent segregation when they planted speltoides and ligustica seed samples obtained from natural (and apparently mixed !) populations. Furthermore, such a scheme easily accounts for the data we obtained upon progeny testing of the Ashkelon population. This also provides a reasonable explanation of the nature of morphological differences between the two types, namely the restriction of these differences to the fruiting spike alone. Such a divergence is rather unexpected in ordinary processes of subspeciation and speciation, but easily accounted for in a case of population dimorphism.

Finally, a model of fruit dimorphism can account for the peculiar mode of inheritance of the manifold differences between the two types : their inheritance in a more or less monohybrid fashion with only rare cases of recombinants. As already proposed by Sears (I94I), this mode of inheritance suggests the presence of a single block of closely linked genes. Again such a block is hardly explicable in terms of ordinary evolutionary divergence. But a system based on such a single block is an essential (and evolutionally well exploited !) means for the establishment of population dimorphism.

In the restriction of morphological differences to a single organ and in the control of these differences by a closely linked block of genes, the situation in the speltoides-ligustica pair resembles the much better known form of population dimorphism in plants, i.e. the floral dimorphism of distyly. In distyly too, manifold morphological differences separate thrum plants from pin plants ; but these differences are restricted to the flower only. In distyly again, a parallel genetic system has evolved; a compound locus-or a block of closely linked genes-is responsible for the establishment of dimorphic populations (Lewis, 1954).

There is, however, a principal difference between floral dimorphism and population dimorphism in fruit structure. Distyly serves to maintain cross-pollination. This is best achieved when--as in sexthrum vs. pin proportions are $\frac{1}{2}: \frac{1}{2}$. It is maintained by means of a $\mathrm{S} / \mathrm{s}$ vs. s/s genotypic structure and by a mating system of legitimate crosses only. Such a rigid requirement for fifty to fifty proportions 
does not exist in cases of fruit dimorphism. Moreover, cross-pollination here is carried out by wind and is apparently completely at random (within and between the two types) resulting in the production of homozygous dominant zygotes. Mixed populations of the ligusticaspeltoides pair show wide variation in the relative proportions of the two types. Such a variation is to be expected, since different habitats may differ in their relative fitness for the two modes of seed dispersal -resulting in different equilibria. On this ground one should not expect a simple population system of heterozygous $v s$. homozygous recessive in cases of genetic dimorphism in fruit structure.

The data available from the Ashkelon population do not permit a final conclusion as to the genotypic structure of mixed speltoidesligustica stands. Most probably such populations contain three genotypes: homozygous speltoides, heterozygous ligustica and homozygous ligustica. It is yet to be shown whether mixed populations have a simple polymorphic structure, i.e. whether the two ligustica genotypes have, during development, equal adaptive values. Seventeen out of the 19 ligustica parents tested were found to be heterozygotes. This is a significantly higher proportion than that expected on a basis of the simple Hardy-Weinberg equilibrium for an 8o per cent. ligustica20 per cent. speltoides population. But the total number of parents tested is admittedly small, and a final evaluation of the genotypic constitution of mixed stands cannot be made until further information has been collected.

Finally, it is noteworthy that pure populations of either type were also encountered, but significantly mostly on the fringes of this group's distribution area. Apparently under the extreme ecological conditions existing here, the balance between competition and co-operation is broken down, and the better adjusted morphic type becomes fixed. This situation conforms with Mather's (1955) model of geographic speciation evolving from pre-existing polymorphism. Such pure populations might represent the beginning of speciation in the $E$. speltoides group.

\section{SUMMARY}

Evidence is presented to show that the two main morphological types recognised in the Egilops speltoides group, i.e. the ligustica type and the speltoides (=aucheri) type, occur as a rule in mixed populations. Progeny tests, as well as observations on pollination behaviour, indicate that such mixed stands are in fact genetically common populations, in which speltoides and ligustica plants are interconnected by virtue of a common mating system with predominant crosspollination.

The conclusion is arrived at that speltoides and ligustica plants cannot be regarded as two independent forms. They are apparently two constituents of dimorphic, largely panmictic populations. They 


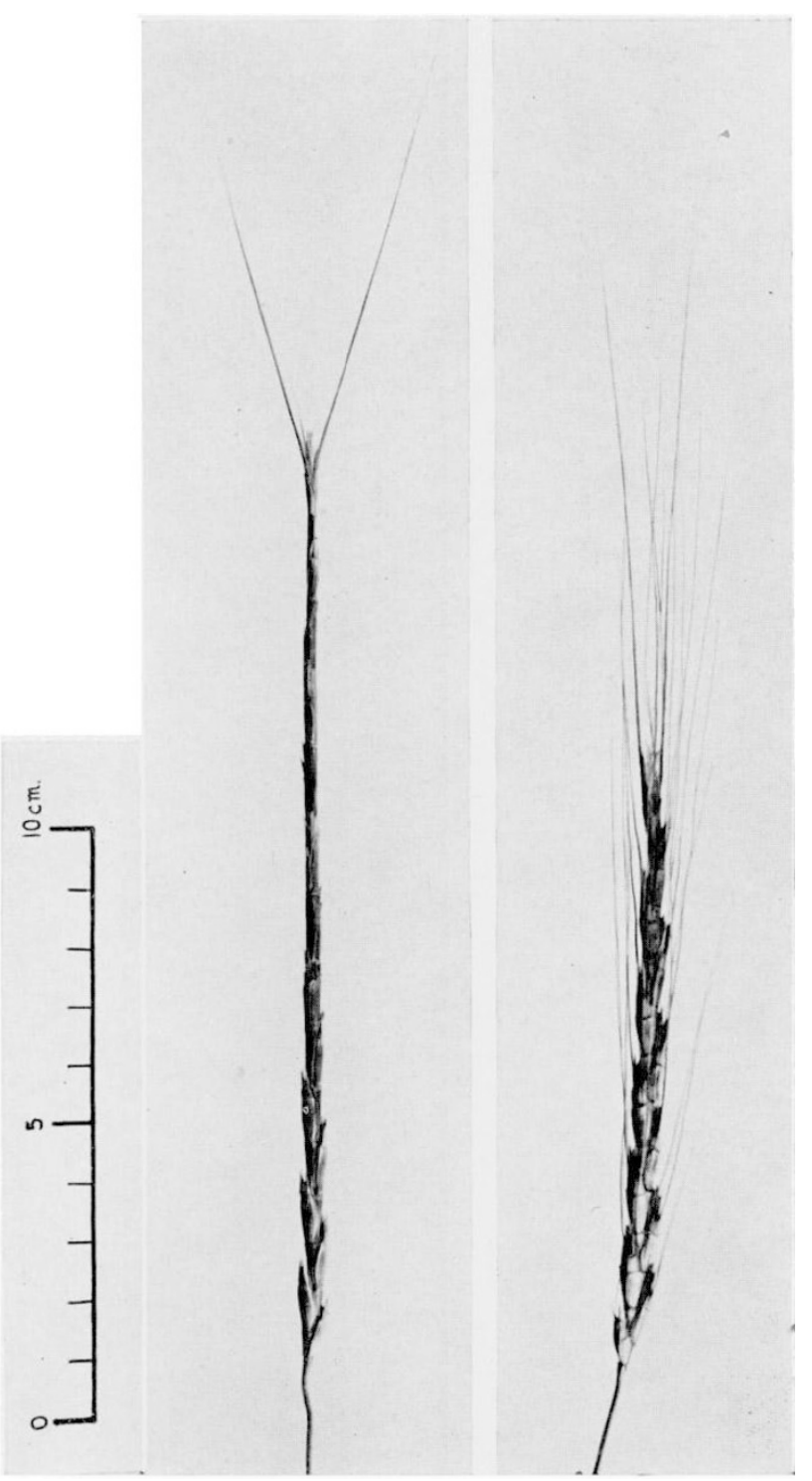

Fruiting spikes of spelloides type (left) and ligustica type (right). 
present us with a case of genetically controlled dimorphism in fruit structure-where two different seed dispersal apparatuses operate on a population level in a complementary way.

Acknowledgment.-The authors are indebted to the Agricultural Research Service of the United States Department of Agriculture for their research grant (FG-IS-I 29) which supported this study.

\section{REFERENCES}

BOWDEN, W. M. 1959. The taxonomy and nomenclature of the wheats, barleys and ryes and their wild relatives. Canad. Journ. Bot., 37, 657-684.

EIG, A. 1929. Monographisch-kritische Uebersicht der Gattung Aegilops. Repert. Spec. Nov., Reg. Veg., Beih. 55, I-228.

kihara, H., AND Lilienfeld, F. A. 1932. Genomanalyse bei Triticum und Aegilops. IV. Untersuchungen an Aegilops $\times$ Triticum und Aegilops $\times$ Aegilops Bastarden. Cytologia, 3, 384-456.

LEWTS, D. 1954. Comparative incompatibility in angiosperms and fungi. $A d t^{\prime}$. Genetics, 6, 235-285.

Mather, K. 1955. Polymorphism as an outcome of disruptive selection. Evolution, 9, $52-6 \mathrm{r}$.

MICZYNSKI, K. 1926. Études génétiques sur le genre Aegilops. I. Expériences avec l'Aegilops speltoides Jaub. et Spach. Acta Soc. Bot. Pol., 4, 20-40.

schiemanN, E. 1928. Zytologische und pflanzen-geographische Beiträge zur Gattung Aegilops (II. Mitteilung). Ber. Deutsch. Bot. Ges., 46, 107-123.

SEARs, E. 1941. Amphidiploids in the seven-chromosome Triticinae. Univ. Missouri Agric. Exper. Sta. Res. Bull., 336, 1-46.

ZHUкOVSKY, P. M. 1928. A critical systematical survey of the species of the genus Aegilops L. Bull. Appl. Bot. Genet. and Plant Breed., I8, 41 7-609.

zOHARY, M. 1937. Die Verbreitungsoekologischen Verhaeltnisse der Pflanzen Palaestinas. I. Die antitelechorischen Erscheinungen. Beih. Bot. Centralblatt, $56 A, 1-155$. 